\title{
The Evolving Role and Use of Echocardiography in the Evaluation of Cardiac Source of Embolism
}

\author{
Fabrizio Celeste, Manuela Muratori, Massimo Mapelli, Mauro Pepi \\ Department of Cardiovascular Sciences, Centro Cardiologico Monzino, IRCCS, University of Milan, 20138 Milan, Italy
}

\section{Abstract}

This report will review the role of echocardiography in the diagnosis of cardiac sources of embolism. Embolism of cardiac origin accounts for around $15 \%-30 \%$ of ischemic strokes. The diagnosis of a cardioembolic source of stroke is frequently uncertain and relies on the identification of a potential cardiac source of embolism in the absence of significant autochthonous cerebrovascular occlusive disease. Transthoracic and/or transesophageal echocardiography serves as a cornerstone in the evaluation, diagnosis, and management of these patients. This article reviews potential cardiac sources of embolism and discusses the role of echocardiography in clinical practice. Recommendations for the use of echocardiography in the diagnosis of cardiac sources of embolism are given including major and minor conditions associated with the risk of embolism.

Keywords: Cardioembolic stroke, transesophageal echocardiography, transthoracic echocardiography

\section{INTRODUCTION}

Echocardiography provides images of cardiac and great vessels anatomy and blood flow and is commonly used for the investigation of patients with acute stroke, transient ischemic attack (TIA), or peripheral embolism. Stroke is the third leading cause of death in several industrial countries. It is estimated that $87 \%$ of all strokes are ischemic, and the remaining $13 \%$ are hemorrhagic. Ischemic strokes may be further subdivided into following types:

1. Thrombosis or embolism associated with large vessel atherosclerosis

2. Embolism of cardiac origin (cardioembolic stroke)

3. Small blood vessel occlusion (lacunar stroke)

4. Other determined cause

5. Undetermined (cryptogenic) cause (no cause identified, more than one cause, or incomplete investigation).

Embolism of cardiac origin accounts for $15 \%-40 \%$ of all ischemic strokes while undetermined (cryptogenic) causes are responsible for $30 \%-40 \%$ of such strokes.

The diagnosis of a cardioembolic source of stroke is frequently uncertain and relies on the identification of a potential cardiac source of embolism in the absence of significant autochthonous

\begin{tabular}{|l|l|}
\hline \multicolumn{3}{|c|}{ Access this article online } \\
\hline Quick Response Code: & \multicolumn{1}{|c|}{ Website: } \\
& www.jcecho.org \\
\hline
\end{tabular}

cerebrovascular occlusive disease. Echocardiography (both transthoracic echocardiography [TTE] and/or transesophageal echocardiography [TEE]) serves as a cornerstone in the evaluation and diagnosis of these patients. ${ }^{[1,2]}$ However, cardioembolic stroke is a heterogeneous entity since a variety of cardiac conditions can predispose to cerebral embolism. These cardiac conditions may be classified as major, minor, or uncertain risk [Table 1]..$^{[3-7]}$

From a pathological point of view, cardioembolic sources of embolism may be classified into three distinct categories: (a) cardiac lesions that have a propensity for thrombus formation (i.e., thrombus formation in the left atrial appendage (LAA) in patients with atrial fibrillation (AF); (b) cardiac masses (i.e., cardiac tumors, vegetations, thrombi, aortic atherosclerotic plaques); and (c) passageways within the heart serving as conduits for paradoxical embolization (i.e., patent foramen ovale [PFO]).

Address for correspondence: Dr. Fabrizio Celeste, Department of Cardiovascular Sciences, Centro Cardiologico Monzino, IRCCS, University of Milan, Via Parea 4, 20138 Milan, Italy. E-mail: fabrizio.celeste@ccfm.it

This is an open access article distributed under the terms of the Creative Commons Attribution-NonCommercial-ShareAlike 3.0 License, which allows others to remix, tweak, and build upon the work non-commercially, as long as the author is credited and the new creations are licensed under the identical terms.

For reprints contact: reprints@medknow.com

How to cite this article: Celeste F, Muratori M, Mapelli M, Pepi M. The evolving role and use of echocardiography in the evaluation of cardiac source of embolism. J Cardiovasc Echography 2017;27:33-44. 
Celeste, et al.: Echocardiography and sources if embolism

\begin{tabular}{|c|c|}
\hline Major risk sources & $\begin{array}{l}\text { Minor or unclear risk } \\
\text { sources }\end{array}$ \\
\hline $\mathrm{AF}$ & Mitral valve prolapse \\
\hline Recent myocardial infarction & Mitral annulus calcification \\
\hline \multicolumn{2}{|l|}{$\begin{array}{l}\text { Previous myocardial } \\
\text { infarction (LV aneurysm) }\end{array}$} \\
\hline Cardiomyopathies & Calcified aortic stenosis \\
\hline \multicolumn{2}{|l|}{ Cardiac masses } \\
\hline Intracardiac thrombus & Atrial septal aneurysm \\
\hline Intracardiac tumors & $\mathrm{PFO}$ \\
\hline \multicolumn{2}{|l|}{ Fibroelastoma } \\
\hline \multicolumn{2}{|l|}{ Marantic vegetations } \\
\hline $\begin{array}{l}\text { Rheumatic valve disease } \\
\text { (mitral stenosis) }\end{array}$ & Giant Lambl's excrescences \\
\hline \multicolumn{2}{|l|}{$\begin{array}{l}\text { Aortic arch atheromatous } \\
\text { plaques }\end{array}$} \\
\hline \multicolumn{2}{|l|}{ Endocarditis } \\
\hline Mechanical valve prosthesis & \\
\hline
\end{tabular}

\section{Clinical and Neurological Evaluation}

Since embolism from a cardiac source accounts for $15 \%-30 \%$ approximately of these cerebral events, a very detailed neurologic and cardiac evaluation should first include the patient's clinical presentation even though there are several limitations in making this clinical diagnosis. Several neurologic and cardiac features (detailed informations on the characteristics of the clinical event, history of the patients, clinical evaluation) may suggest a cardioembolic origin. Moreover, evidence of embolism to other organs suggests that a cardioembolic source is likely.

As concerning the neurological evaluation, clinical and imaging findings may suggest a cardioembolic stroke mechanism:

1. Abrupt onset of stroke symptoms, particularly in AF, with lack of preceding TIA and severe first-ever stroke

2. Striking stroke severity in the elderly (NIH-stroke scale $\geq 10$; age $\geq 70$ years)

3. Previous infarctions in various arterial distributions.

a. Multiplicity in space (infarct in both the anterior and posterior circulation or bilateral)

b. Multiplicity in time (infarct of different age)

4. Other signs of systemic thromboembolism (e.g., edge-shaped infarctions of kidney or spleen; Osler splits; Blue toe-syndrome)

5. Territorial distribution of the infarcts involving cortex or subcortical "large lenticulostriate infarct"

6. Hyperdense midcerebral artery (MCA) sign (as long as without severe ipsilateral internal carotide stenosis)

7. Rapid recanalization of occluded major brain artery (to be evaluated by repetitive neurovascular ultrasound).

An accurate clinical evaluation may easily raise the suspicion of a cardioembolic even in the presence of known structural heart disease or of clinical signs of cardiac diseases (i.e., arrhythmias, heart murmurs). However, the presence of a potential cardioembolic source of embolism does not itself justify the diagnosis of cardioembolic stroke or TIA since atherosclerotic cerebrovascular disease and cardiac disease often coexist.

The most frequent causes of cardiogenic stroke are AF, left ventricular (LV) dysfunction (congestive heart failure), valve disease and prosthetic valves, intracardiac right-to-left shunts (PFO, particularly in conjunction with atrial septum aneurysm), and atheromatous thrombosis of the ascending aortic arch. From an epidemiological point of view, ${ }^{[1,7]}$ there is a history of AF in around one-half of cases, of valvular heart disease in one-fourth, and of LV mural thrombus in almost one-third.

TEE has revolutionized the search for cardiac sources of embolism because of its (near) noninvasive nature and its relatively good sensitivity and high specificity. As opposed to lacunar or atherothrombotic stroke, the outcome after cardiogenic stroke is particularly poor with $50 \%$ mortality after 3 years and this is an another important reason why cardiogenic sources of emboli must be identified whenever possible.

Clinically, the most important cause of cardiogenic brain embolism is AF both paroxysmal and chronic. Any history of bouts of tachycardia or of periods of arrhythmia may suggest intermittent AF. The TOAST criteria are the most frequently used classification of stroke in epidemiological or genetic studies and refer to (1) large artery atherosclerosis (artery-to-artery embolus, large artery atherothrombosis), (2) cardiac embolism, (3) cerebral small artery occlusion (lacunar stroke), (4) stroke of another determined etiology (rare etiologies), and (5) stroke of undetermined etiology. Categories 2 and 5 are of particular interest for echocardiography. Echocardiography in patients with $\mathrm{AF}$ enables risk stratification with respect to recurrent stroke by measuring the size of the atrium. The annual risk of stroke is $1.5 \%$ in cases with a normal left atrial diameter but raises significantly in patients with an enlarged atrium.

The extension and site of the infarct on computed tomography (CT) or magnetic resonance imaging (MRI) can deliver important clues toward a cardiogenic embolic stroke mechanism. This is the case if the infarct shows a cortical extension, multiplicity, or bilaterality. However, there is also a specific type of subcortical infarct, the "large lenticulostriate infarct" which typically indicates an embolic stroke mechanism. Multiplicity of lesions involving both the anterior and posterior circulation and/or both hemispheres is highly suggestive of cardiogenic embolism.

\section{Specific Recommendations in Diseases Related to Cardioembolic Events \\ Myocardial infarction and heart failure}

Thromboembolism is a severe complication in patients with heart failure. ${ }^{[8,9]}$ While the detection of an intracardiac thrombus may be the primary culprit for a thromboembolic event, a variety of factors are also associated with heart 
failure and predispose to thrombosis. These include vascular disease, procoagulative status, and impaired flow. The role of TTE is to assess the size and function of the LV (global and regional), estimate the LV ejection fraction (LVEF) quantitatively, and assess other structural abnormalities such as valvular, pericardial, or right ventricular abnormalities and intracardiac masses that may be related with systemic embolization risk. Etiologies of LV dysfunction leading to heart failure may be ischemic or nonischemic. Both lead to heart failure and can provide the anatomical substrate for LV thrombus formation. Intracardiac thrombus is a common finding in patients with ischemic stroke and may represent an indication for long-term anticoagulation to reduce the threat of further stroke and possibly to dissolve the thrombus. As concerning heart failure and cardiomyopathies, there are a number of factors that may predispose to thromboembolic events including low cardiac output, very dilated ventricles, extensive wall motion abnormalities and also AF, particularly for atrial thrombus formation.

Thrombus formation following myocardial infarction is now rare since the majority of patients with acute myocardial infarction undergo prompt thrombolysis and revascularization. ${ }^{[10-13]}$ The exact incidence of LV thrombus following acute myocardial infarction is not known as studies have been performed over several chronological periods while the treatment of acute myocardial infarction was changing. Early data suggest that in the setting of acute myocardial infarction, LV thrombus may be present in $7 \%-20 \%$ of patients, most frequently in acute anterior or apical myocardial infarction. With chronic ventricular aneurysm, the prevalence of LV thrombus may increase up to $50 \%$. Despite this, rather high incidence of postmyocardial infarction thrombus formation, the prevalence of thromboembolic events is low. Weinsaft et al ${ }^{[11]}$ used cardiac MRI in a large cohort of patients with LV systolic dysfunction (LVEF $<50 \%$ ) predominantly of ischemic etiology and found the prevalence of thrombus to be $7 \%$ in this population. Patients with thrombus were more likely to have previous myocardial infarction, more advanced systolic dysfunction, and more extensive myocardial scarring by delayed enhanced MRI.

$\mathrm{LV}$ thrombus is defined as a discrete echo dense mass in the $\mathrm{LV}$ with defined margins that are distinct from the endocardium and seen throughout systole and diastole. It should be located adjacent to an area of the LV wall which is hypokinetic or akinetic and seen from at least two views (usually apical and short axis). Care must be taken to exclude false tendons and trabeculae and of course rule-out artifacts, which constitute the most common false diagnosis of a thrombus. Sensitivity and specificity of the echocardiographic diagnosis of LV thrombus are in the range of $95 \%$ and $86 \%$, respectively, in an experienced echocardiography laboratory. However, very often, the LV apex cannot be clearly defined and the presence or absence of a thrombus may be very difficult to establish. It is, therefore, useful to use a contrast ultrasound agent injected intravenously, which will then clearly identify the presence or absence of a thrombus. ${ }^{[12,13]}$ The use of contrast improves image quality and allows for a more accurate assessment of LV volumes and LVEF and thrombus detection. TEE has little to offer in the detection of LV apical thrombus.

Several thrombus characteristics should be annotated:

- Shape: LV thrombus may be flat (mural), lying along the LV wall or protruding within the cavity. It may be homogeneously echogenic or present a heterogeneous texture often with central lucency

- Dimensions: Linear dimensions in at least 2 planes and area may be easily annotated

- Motion: Thrombi may be fixed along LV wall or present an independent motion to a variable extent. Motion may involve the entire thrombus or more commonly a portion of the thrombus. Motion is independent of the underlying myocardium and that characteristic clearly distinguishes a true thrombus from an artifact. Color Doppler tissue imaging may further facilitate this differential diagnosis.

The risk of peripheral emboli is higher in patients with larger thrombus size, those with protruding and mobile LV thrombi, and in the older patients.

Figures 1 and 2 show examples of LV thrombi and usefulness of echocontrast agents in suboptimal TTE.

\section{Atrial Fibrillation}

A thrombus located in the left atrium or, more precisely, in the LAA is the most prevalent source of cardioembolic events and is typically associated with atrial arrhythmias such as $\mathrm{AF}$ and atrial flutter ${ }^{[14-24]}$ TEE is the imaging modality of choice for the evaluation of LAA anatomy and function. The LAA may be unilobular or multilobular. Four different morphologies have been used to categorize the LAA: cactus,

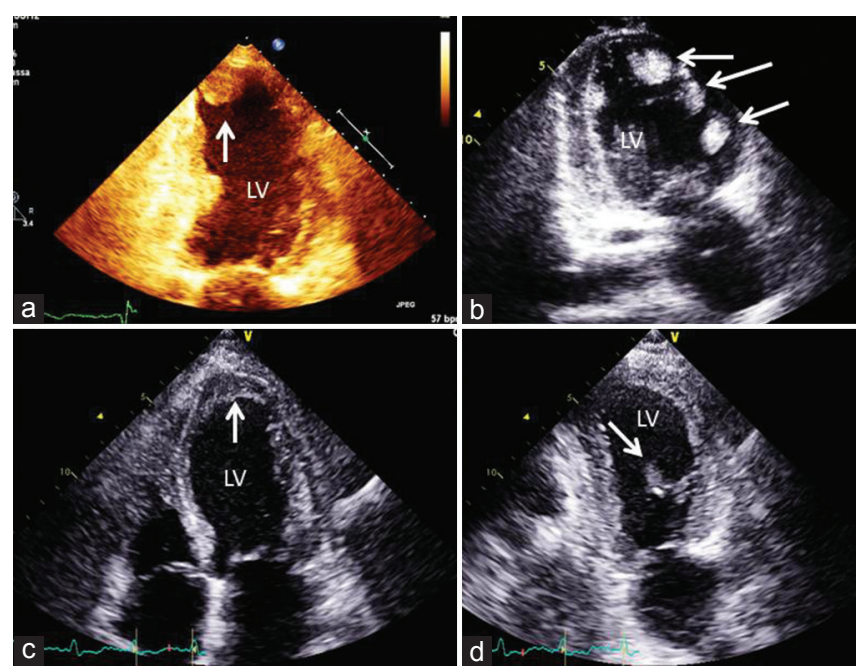

Figure 1: Apical transthoracic views showing (arrows) four different cases: (a) apical protruding left ventricle thrombus; (b) multiple left ventricle thrombi in a idiopathic cardiomyopathy; (c) apical mural stratified thrombus; (d) uncommon mobile left ventricle thrombus in the mid anterolateral wall. LV: left ventricle. 
chicken wing, windsock, and cauliflower. Patients with chicken-wing LAA morphology may be less likely to have thromboembolic events compared with those with other LAA morphologies.

The link between AF and cerebral or systemic embolism is important and complex. Its importance derives from the high prevalence of $\mathrm{AF}(0.4 \%-1 \%$ in the general population, increasing to $9 \%$ in persons aged 80 years or older) and from the frequent occurrence of stroke and embolism, ranging from $1 \%$ (low-risk patients) to up to $15 \%$ event/year (high-risk patients).

Echocardiography has routinely become established in guidelines ${ }^{[14]}$ for the management of AF. TTE has great importance in identifying etiological causes underlying $\mathrm{AF}$ such as valvular heart disease; left and right atrial dimensions; LV dimensions and thickness; LV systolic and diastolic function; right ventricular dimensions and function; tricuspid regurgitation with right ventricular systolic pressure estimate; pericardial disease.

Moreover, with the increasing use of procedures of radiofrequency ablation and of LAA closure, echocardiography has gained an important role in the selection, guidance, and follow-up of percutaneous and surgical interventions.

Thrombi formation in the cardiac cavities is mainly due to blood stasis. During sinus rhythm, the contractile activity of LAA with its vigorous emptying of blood flow usually prevents the formation of thrombi in the LAA despite its cul-de-sac shape and its plurilobate anatomical structure. The onset of atrial dysfunction renders the LA prone to the formation of thrombi within its cavity.

TEE is the gold-standard technique to detect LAA thrombi. Thrombi are seen as echo reflecting masses in the atrial body or in the LAA (often in its apex), distinct from the underlying endocardium, observed in more than one imaging plane, and not related to pectinate muscles [Figure 3]. TEE is also able to detect signs of LAA dysfunction, often associated with or preceding the thrombus formation, such as low LAA emptying velocities and spontaneous echo contrast (SEC). ${ }^{[23,24]}$ Low LAA emptying velocities are well depicted with pulsed Doppler
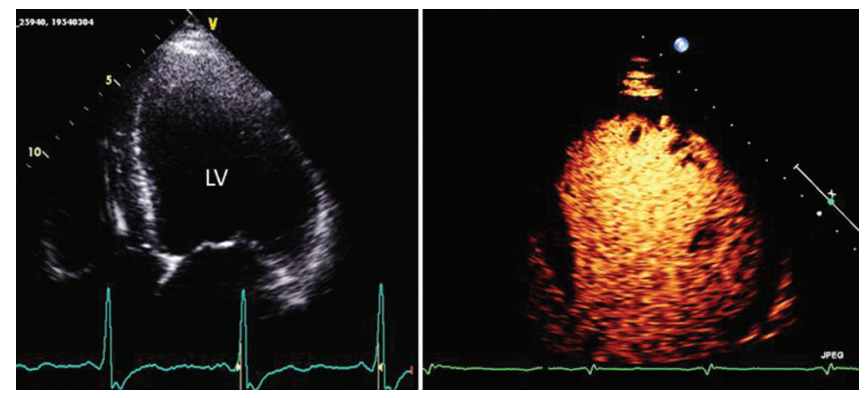

Figure 2: Transthoracic apical four chamber view: Left panel: Suboptimal visualization of left ventricle wall and apex: Right panel: contrast echocardiography shows normal opacification of the left ventricle cavity. LV: left ventricle.
TEE, when the maximum peak of emptying velocity is lower than $30-40 \mathrm{~cm} / \mathrm{s}$.

The assessment of embolic risk in $\mathrm{AF}$ is crucial to indicate anticoagulant therapy in each patient, counterbalancing the hemorrhagic risk. The risk stratification of patients with AF is based on clinical predictive factors according to a validated scheme named CHADS2. In the difficult decision to indicate lifelong anticoagulation, several echocardiographic factors can help in predicting the thromboembolic risk [Table 2]. Factors independently associated with increased thromboembolic risk are LAA thrombi, dense SEC, LAA peak flow velocities $\leq 20 \mathrm{~cm} / \mathrm{s}$, and complex aortic plaques.

Therefore, echocardiographic data are independent predictors of thromboembolism and can offer additional information, mostly in the subgroup of patients at intermediate risk and in all cases with doubts on the risk/benefit ratio for the therapeutic choice.

\section{Transesophageal echocardiography to guide cardioversion}

The most important role of TEE in AF is to guide short-term anticoagulation for cardioversion. In patients with AF lasting more than $48 \mathrm{~h}$, besides the "conventional approach" with oral anticoagulation for at least 3 weeks precardioversion, a "short-term TEE-guided approach" can be used. This

Table 2: Echocardiographic predictors of embolic risk in patients with atrial fibrillation

\section{Echocardiographic risk factors}

LV systolic dysfunction $(\mathrm{EF}<35 \%)$

Complex aortic plaques*

LAA thrombi or spontaneous echo contrast*

LAA dysfunction (emptying blood flow velocities $<20 \mathrm{~cm} / \mathrm{s}$ and/or reduced contraction at $\mathrm{M}$-mode)

*Identified only at TOE. LAA=Left atrial appendage,

TOE=Transesophageal echocardiography, LV=Left ventricular

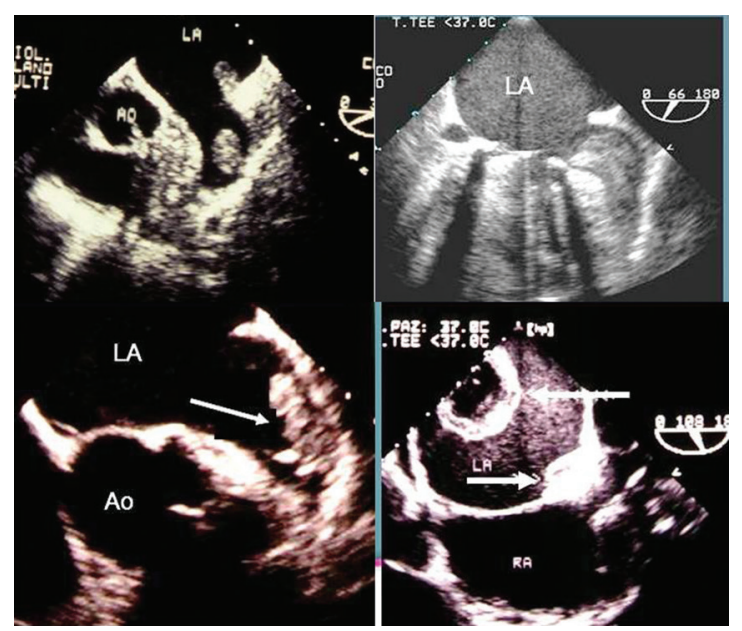

Figure 3: Transesophageal echocardiography imaging of the left atrium and left atrium appendage in four different cases with left atrium appendage thrombi (arrows). Each case is characterized by different dimension, shape, and echogenicity of thrombus. 
"TEE-guided approach," based mainly on the results of the ACUTE study, ${ }^{[25]}$ avoids the 3 weeks of precardioversion anticoagulation in patients with no evidence of thrombi in the LA/LAA at TEE. In patients with thrombus, oral anticoagulation is usually performed lifelong (or a second TEE after anticoagulants should be performed), abolishing the cardioversion because of the high thromboembolic risk. There is a consensus on 4 weeks of oral anticoagulation after cardioversion with either strategy because of the possible occurrence of thromboembolism in the early postcardioversion period even in the absence of thrombi in the precardioversion TEE. These rare embolic events are due to the postcardioversion LAA dysfunction (the so-called "atrial stunning"), which causes atrial stasis and provides a milieu for the formation of new thrombi. ${ }^{[25,26]}$

Table 3 shows in summary the role of TTE and TEE with AF.

\section{Patent Foramen Ovale}

PFO, the remnant of an embryologic circulatory bypass of the lungs, is present in approximately one-fourth to one-third of all adults. The prevalence of PFO decreased with age, from $34 \%$ in the group aged $0-30$ years to $20 \%$ in the group aged 80-99 years. Thus, the finding of a PFO should be considered a normal variant rather than a pathologic finding.

The foramen ovale is a slit-like communication between the left and right atrium bounded by two thin septal membranes representing the septum secundum (on the right atrial side) and the septum primum (on the left atrial side), in the cranial portion of the fossa ovalis, the thin part of the atrial septum. Most of the time, the PFO is kept closed by a positive left-to-right atrial pressure gradient which holds the two septal membranes together. If the right atrial pressure exceeds the left atrial pressure, however, as in the Valsalva maneuver or due to the right atrial pressure increase, a right-to-left shunt flow through the PFO ensues.

There is a wide anatomic range in size and functional significance of PFO, from the described frequent minimal variant to rarer forms, where there is a permanent open communication between the atria, leading to a predominant left-to-right shunt with occasional shunt reversal. An atrial septal aneurysm is diagnosed if there is a fixed displacement or a mobile excursion of the fossa ovalis region of the atrial septum toward the right or left atrium, or both, exceeding $10 \mathrm{~mm}$ from the midline (a line from the basal part of the interventricular septum to the insertion of the septum secundum in the atrial wall). The potential mechanism may be that the aneurysm may act as like a net capturing thrombi and conveying them to the PFO.

The association of PFO and otherwise unexplained neurological ischemic insults has been intensively studied. ${ }^{[27-44]}$ The underlying concept of paradoxical embolism of venous thrombi through the PFO has been well documented in the context of acute pulmonary embolism. However, while many authors have confirmed the statistical association between PFO and unexplained neurological events in young patients, the causality has not been conclusively established. This is an area of clinical uncertainty and ongoing debate, rendering it difficult to give firm recommendations. ${ }^{[1,2,32,34,39,44]}$ The following statements are fair in view of the available evidence and are reported in Table 4. These points should be integrated into the decisions on patient management.

\section{Technical points of patent foramen ovale detection}

Transcranial Doppler often provides the first clue to the existence of a right to left shunt by detecting microbubbles in the MCA after intravenous fluid injection. However, TEE is

\begin{tabular}{l} 
Table 3: Transthoracic echocardiography and \\
transesophageal echocardiography role in atrial \\
fibrillation \\
\hline TTE \\
To detect an underlying pathology affecting management or therapeutic \\
decisions (ischemic heart disease, valvulopathy, cardiomyopathy, or \\
reduced ventricular function) \\
Before cardioversion of atrial flutter (since this arrhythmia is often a \\
marker of severe heart disease) \\
To indicate, guide and follow-up invasive surgical procedures, such as \\
substrate AF ablation (RF or surgical) or LAA closure \\
The addition of TEE in patients with AF is indicated \\
In guiding short-term anticoagulated cardioversion \\
In clinically selected cases (preablation of AF and preclosure LAA, \\
suspected aortic arch atherosclerosis, recurrence of embolism during \\
correct anticoagulation) \\
In determining the risk for future embolism (study of LAA function) \\
\hline TEE=Transesophageal echocardiography, TTE=Transthoracic \\
echocardiography, AF=Atrial fibrillation, LAA=Left atrial appendage, \\
RF=Radiofrequency
\end{tabular}

Table 4: Summary of available statements concerning patent foramen ovale and neurological events

Paradoxical embolism through a PFO is a rare cause of neurological ischemic events, except in the context of acute pulmonary embolism with a rise in right atrial pressure

In the absence of a demonstrable elevation of right atrial pressure, caution should be exercised to incriminate PFO in unexplained neurologic events. However, in the absence of more likely causes, paradoxical embolism through a PFO may be assumed in the following circumstances

Young age. Over the age of 55 years, the likelihood of atherosclerotic disease or occult paroxysmal AF as a source of embolism is far higher than that of paradoxical embolism through a PFO. Two population-based study of subjects over 39 years of age found no excess ischemic neurological events in subjects with versus subjects without PFO although some controversy over this issue continues

The presence of an atrial septal aneurysm additional to a PFO is associated with a marked increase in recurrent unexplained neurologic events

Large provokable right-to-left shunts have shown a stronger association with unexplained neurologic events than small shunts. Shunt quantification is difficult, but the number of bubbles crossing the septum either spontaneously or after a Valsalva maneuver gives a rough idea of shunt size. More than 20 bubbles have been cited to indicate a "large PFO" 
traditionally the gold standard for the detection of PFO even though in the presence of good image quality, transthoracic echo is sufficient to detect the presence of a PFO. ${ }^{[45,46]}$ Performance of a valid Valsalve maneuver must be ensured with both methods. Figure 4 demonstrates the usefulness of TTE with contrast agents in imaging right-to-left shunt in cases with different degrees of shunt.

A PFO is diagnosed if intravenous microbubbles (agitated infusion solutions, right heart contrast agents, or saline-blood mixtures) passing from the right atrium into the left atrium, either spontaneously or after a Valsalva maneuver is directly observed. A right-to-left or left-to-right shunt on color Doppler clearly originating from a passage between the two septa in the fossa ovalis is also diagnostic. Although TEE is still regarded as the gold standard for PFO detection, current echo machines equipped with harmonic imaging have an equivalent sensitivity to visualize right-to-left shunt through a PFO. Table 5 summarizes recommendations regarding technical and clinical considerations on PFO diagnosis and therapy.

\section{Aortic Atherosclerosis}

Imaging of the aorta is an essential part of the evaluation of embolic stroke and peripheral embolization. ${ }^{[47-57]}$ Atherosclerotic plaque is the most common source of embolism originating from the aorta. In rare instances, embolism can arise from aortic tumors. Atherosclerotic plaques in the aorta may give rise to two different types of emboli (thromboemboli and cholesterol crystal emboli) and two different syndromes of arterioarterial embolism (aortic thromboembolism syndrome and cholesterol emboli syndrome).
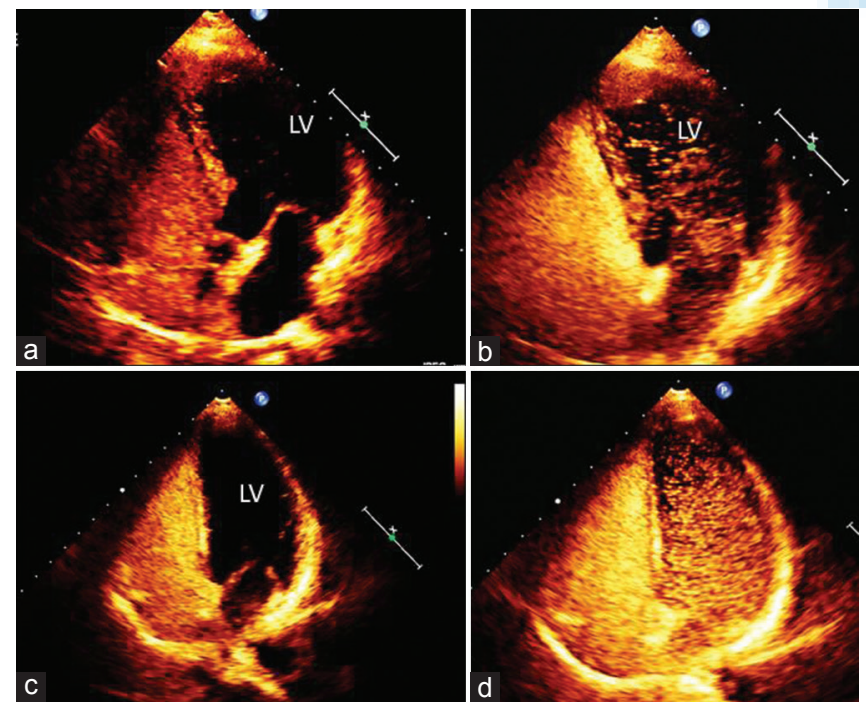

Figure 4: Apical four chamber view of two cases of patent foramen ovale before ( $a$ and $c$ ) and after Valsalva maneuver ( $b$ and $d)$. (a) Baseline contrast without right-to-left shunt; (b) same case after Valsalva maneuver: microbubbles in the left ventricle cavity indicating moderate shunt; (c) baseline contrast without right-to-left shunt; (b) same case after Valsalva maneuver: microbubbles in the left ventricle cavity indicating severe shunt.
Aortic atherosclerosis is well known to increase with advancing age and is related to traditional cardiovascular risk factors such as hypertension, hypercholesterolemia, diabetes mellitus, and smoking. The prevalence of aortic atheromas on TEE varies depending on the population studied. In a community study, aortic atheromas were present in $51 \%$ of randomly selected residents aged 45 years or older, with a greater prevalence in descending aorta. Complex atheromas were present in $7.6 \%$. Aortic arch atherosclerosis is found in $60 \%$ of patients 60 years or older who had cerebral infarction. In the stroke prevention in $\mathrm{AF}$ (SPAF), ${ }^{[55]}$ investigators reported that $35 \%$ of patients with "high risk" nonvalvular AF had complex aortic plaque (mobile, ulcerated size $>4 \mathrm{~mm}$ ). During 13 months of follow-up, patients with complex aortic atheromatous plaque had a fourfold increased rate of stroke, compared to plaque-free patients. Clots floating in the aorta frequently become inserted to atherosclerotic plaque and have a high embolic risk. Another complication of aortic atherosclerosis is cholesterol embolization syndrome, spontaneous, or secondary to an invasive vascular procedure. Similarly, ascending aorta and arch atheromas proved to be a highly significant risk factor for intraoperative stroke.

\section{Aortic atherosclerosis diagnosis}

The detection, characterization, and quantification of aortic plaques can be accomplished by TEE, CT, or MRI. Aortic atheromas are characterized by irregular intimal thickening of at least $2 \mathrm{~mm}$. The following grading system is used to classify aortic atherosclerosis: Grade I: intimal thickening $<4 \mathrm{~mm}$; Grade II: diffuse intimal thickening $\geq 4 \mathrm{~mm}$; Grade III: atheroma $<5 \mathrm{~mm}$; Grade IV: atheroma $>5 \mathrm{~mm}$; and Grade V: any mobile atheroma (modified from Montgomery et al. ) $^{[8]}$ [Figure 5].

Based on their morphology, aortic atheromas are classified as either simple or complex plaques. Figure 6 shows examples of complex and mobile aortic plaques. Although the usefulness of TTE is limited for assessing aortic atherosclerosis, it has been shown to play a role in the diagnosis of aortic arch atheromas using suprasternal harmonic imaging.

The advantages of TEE over other noninvasive modalities (CT and MRI) include its ability to assess the mobility of

\section{Table 5: Summary of technical and clinical statements} concerning patent foramen ovale

TEE is traditionally the gold standard for the detection of PFO; however,
in the presence of good image quality, transthoracic echo is sufficient to
detect the presence of a PFO. Performance of a valid Valsalve maneuver
or strong cough must be ensured with both methods
The etiologic role of paradoxical embolism through a PFO in unexplained
stroke should be assumed with great caution and discussed with the neurologist.
Factors that argue in favor of this mechanism and that would suggest an
indication for either anticoagulation or PFO closure are:
Temporal relationship of the neurological event with venous thrombosis
Young age (typically <55 years) and absence of other potential causes
Presence of an atrial septal aneurysm
Presence of a large spontaneous or provokable right-to-left shunt $\mathrm{PFO}=$ Patent foramen ovale, $\mathrm{TEE}=$ Transesophageal echocardiography 


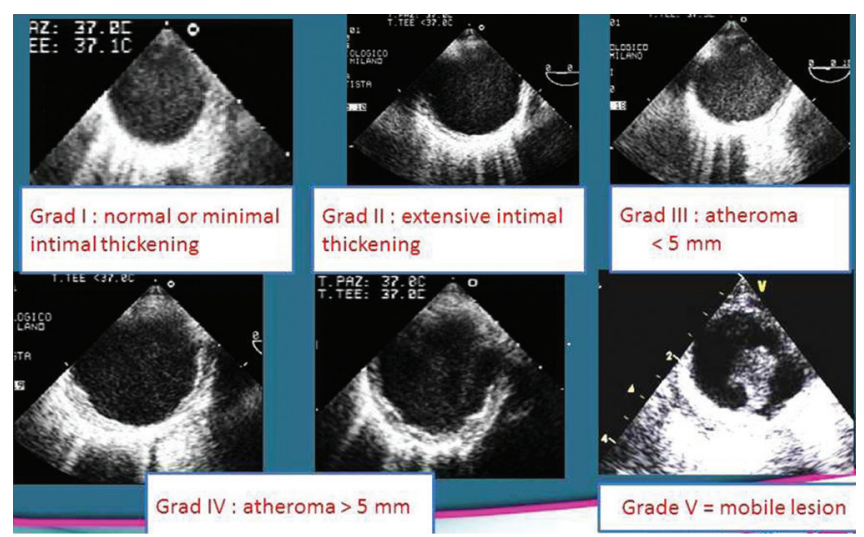

Figure 5: Grading (Montgomery classification) of severity of aortic atherosclerosis.

plaque in real time. Increasing plaque thickness $\geq 4 \mathrm{~mm}$ imparted a greater embolic risk and mobile lesions (thrombi) superimposed on aortic atheromas are also known to increase the risk of embolism.

\section{Cardiac Masses}

Primary cardiac tumors are very rare (autoptic prevalence of $0.05 \%)$. Most primary cardiac tumors are histologically benign but may have malignant clinical course due to their often high embolic potential. The two most common primary cardiac tumors in adults are myxoma and papillary fibroelastoma both of which often present with stroke or other embolism..$^{[59-61]}$ The strokes may occur because of embolism of the tumor itself or because of dislodgement of an associated thrombus. Primary malignant tumors of the heart are rare and are mostly sarcomas. Because they are located predominantly in the right heart, they may lead to pulmonary rather than systemic embolism. Secondary tumors due to metastatic disease are 20 times more common (1\% in autopsy series) than benign cardiac tumors but are infrequently implicated as a cardiac source of embolism. The most common malignant tumors of the heart include melanomas as well as metastases from lung, breast, colon, and stomach cancers.

Two-dimensional and three-dimensional (3D) echocardiographic imaging can establish the location, appearance, size, and mobility of cardiac tumors. Color and spectral Doppler is useful in determining the hemodynamic consequences of the tumors, mainly obstruction and valve stenosis. It is generally the only imaging modality required preoperatively although MRI or CT may also be indicated in selected cases.

Cardiac myxoma is the most common benign primary tumor of the heart, accounting for approximately $30 \%-50 \%$ of all primary cardiac tumors. It is an endocardial-based neoplasm of uncertain histogenesis that, morphologically, is unique and not seen in extracardiac locations. Mean age at presentation is 50 years and approximately two-thirds of patients are women. Almost $90 \%$ of myxomas occur in the LA as polypoid lesions

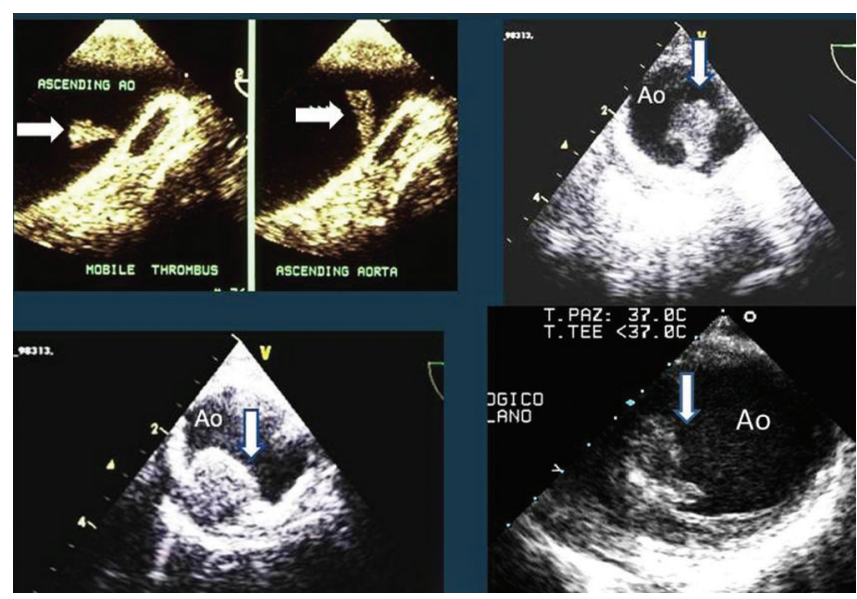

Figure 6: Transesophageal echocardiography of the ascending aorta (left upper panel) and the descending thoracic aorta (other three panels) in four cases with mobile and complex plaques.

attached to the oval fossa; sometimes, they involve the right atrium (15\%) or the left or right ventricle (5\% each); in 5\% of case, they show multiple locations. In over $50 \%$ of patients, LA myxomas cause symptoms of mitral valve stenosis (dyspnea and orthopnea from pulmonary edema or heart failure). Embolic phenomena occur in $30 \%-40 \%$ of patients. Smooth surfaced tumors are more likely to produce valvular obstruction while polypoid and myxoid ones are more likely to embolize [Figures 7 and 8].

Cardiac myxomas typically appear as a mobile mass attached to the endocardial surface by a stalk, usually arising from the fossa ovalis. Myxomas with this appearance can be confidently diagnosed by TTE although small tumors or those that involve the right heart may require TEE for diagnosis. 3D echocardiography has also been used to more fully characterize atrial myxomas. Since myxomas are usually small and mobile, they are typically better defined by echocardiography than by either MRI or CT. If the narrow stalk is not visible, the diagnosis cannot be made by echocardiography and further imaging, MRI or CT, is necessary to show the tumor's margins and to exclude tumor infiltration. The major complication of myxoma is embolization, especially of myxoid, friable, familial ones.

\section{Papillary fibroelastoma}

Fibroelastomas are by far the most common valve-associated tumors, accounting for more than $85 \%-90 \%$ of them. Myxomas and fibromas account for the remainder, whereas malignant tumors involving the valves are very rare. Histologically, fibroelastomas are avascular papillary structures lined by endothelial cells and are often mistaken for cardiac myxoma. Papillary fibroelastomas are small, generally $0.5-2.0 \mathrm{~cm}$ in diameter, and are often confused with vegetations [Figure 9]. Making this distinction is difficult because of the similarity in the echocardiographic appearance. A correct diagnosis therefore depends on the clinical setting and the presence or absence of signs of infection. These tumors are usually attached 


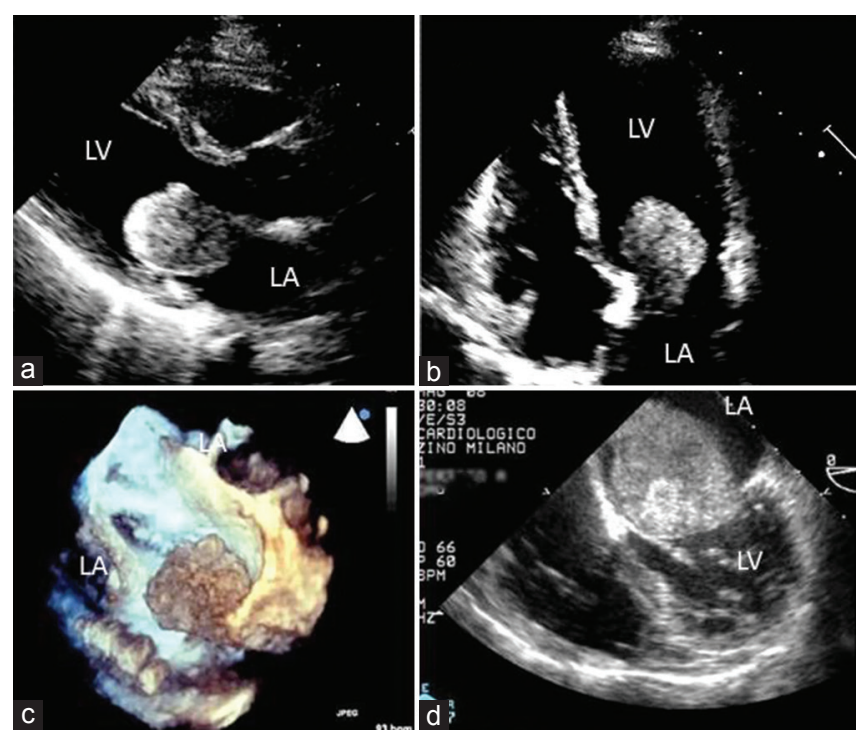

Figure 7: Left atrial myxomas. (a) Parasternal Iong-axis view showing wedging of the myxoma into the mitral valve; (b) same case (four chamber view); (c) three-dimensional transesophageal echocardiography visualization of a left atrium myxoma attached to the posterior wall of the left atrium proximal to the pulmonary vein; (d) transesophageal echocardiography four chamber view of a large left atrium myxoma obstructing the mitral valve.
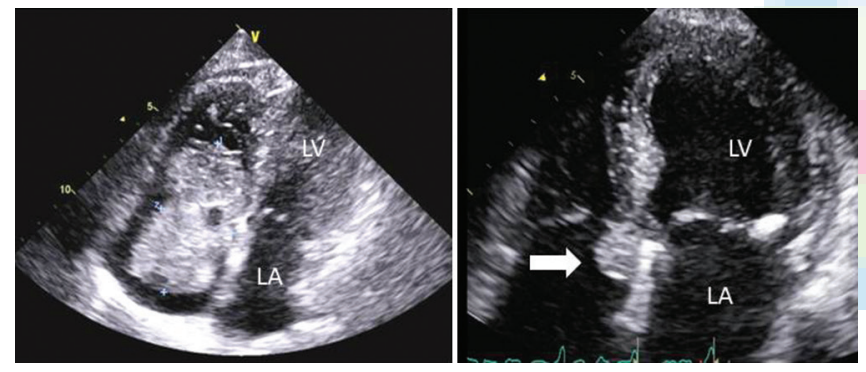

Figure 8: Adapted transthoracic four chamber views of a huge right atrial myxoma (left panel) and small one (arrow, right panel).
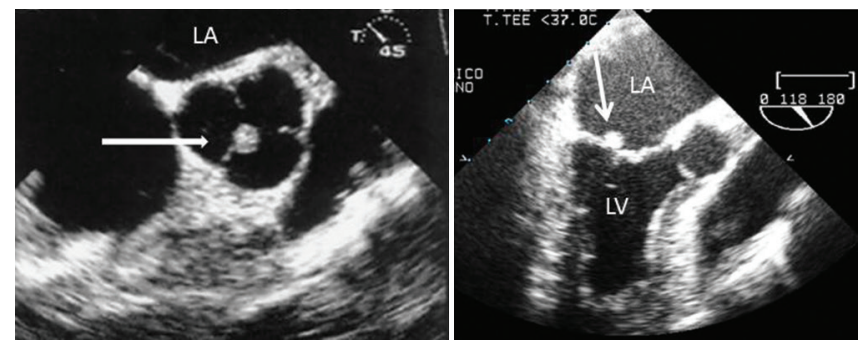

Figure 9: Small aortic fibroelastoma of the aortic valve (short axis transesophageal echocardiography view-arrow) and of a small Mitral valve fibroelastoma (transesophageal echocardiography three chamber view-arrow).

to the downstream side of the valve by a small pedicle and are irregularly shaped with delicate frond-like surfaces; tumor mobility is the independent predictor of death or nonfatal embolization and significant valvular regurgitation is rare. Differential diagnosis with Lambl's excrescences is difficult and controversial; generally Lambl's excrescences are smaller and frequently seen on an otherwise normal valve in elderly patients. Whether the two pathologies represent different entities remains controversial.

\section{ENDOCARDITIS}

Embolic events represent one of the most severe complications of infective endocarditis (IE), particularly in case of cerebral embolism, which is associated with an increased morbidity and mortality. ${ }^{[62-75]}$ The rate of systemic embolism in IE is very high. It has been estimated to be $10 \%-50 \%$ of IE. However, its exact incidence is unknown, with a large number of embolic events being clinically silent. In the majority of cases, IE is clinically suspected because of fever and/or other clinical findings suggestive of IE. However, in some situations, these features are absent and IE is diagnosed on a systematic TEE performed because of unexplained embolic event.

Three echocardiographic findings are considered as major criteria for endocarditis, including vegetation, abscess, and new dehiscence of a prosthetic valve. Among them, the presence of vegetation is a hallmark of IE. Vegetation typically appears as a chaotic mass with acoustic properties different from that of the underlying cardiac structure, adherent to a valve leaflet and with mobility independent to the associated valve. Less frequently, vegetations are localized on mural endocardium or papillary muscles. Echocardiography must be performed in all cases of suspected IE. It combines the advantages of diagnosing IE and assessing the severity of valve damage, detecting cardiac complications, and predicting prognosis and embolic risk. TTE must be performed first and has sensitivity of about $60 \%$ for the diagnosis of vegetation. TEE is mandatory in cases of doubtful TTE, in prosthetic and pacemaker IE, and when an abscess is suspected. TEE enhances the sensitivity of TTE to about $85 \%-90 \%$ for the diagnosis of vegetation and the additive value of TEE is even more important for the diagnosis of abscess and other forms of perivalvular extension.

The sensitivity of echocardiography (both TTE and TEE) is lower in patients with a prosthetic valve or an intracardiac device. Similarly, identification of vegetations may be difficult in the presence of mitral valve prolapse (MVP) with valve thickening if vegetations are very small $(<2 \mathrm{~mm})$ or already embolized. For these reasons, TTE/TEE must be repeated after a few days delay after an initially negative echocardiographic examination if the clinical suspicion remains high.

Echocardiography plays a major role in predicting embolic events ${ }^{[65-71]}$ although this prediction remains difficult in the individual patient. Location of the vegetation on the mitral valve and the increasing or decreasing size of the vegetation under antibiotic therapy have also been associated with an increased embolic risk. The risk of new embolism increases with the increasing size of the vegetation, with patients with very large $(>15 \mathrm{~mm})$ and mobile vegetations having the highest risk, especially in staphylococcal mitral valve endocarditis. 
The risk of a new embolism is highest during the $1^{\text {st }}$ day following the initiation of antibiotic therapy and decreases after 2 weeks although some degree of risk persists indefinitely in the presence of vegetation. For this reason, the benefit of surgery to prevent embolization would be greatest during the $1^{\text {st }}$ week of antibiotic therapy, when the embolic rate is highest. Figure 10 shows four different cases of endocarditis.

\section{Prosthetic Valves/Intracardiac Devices}

Intracardiac devices and prosthetic valves represent a major source of embolism. The presence of an intracardiac material in the setting of an embolic event raises a high level of suspicion of a cardioembolic source.

\section{Prosthetic valves}

Two complications of prosthetic valve replacement must be suspected when an embolic event occurs in a patient with a prosthetic valve: prosthetic valve IE (see endocarditis) and prosthetic thrombosis. Prosthetic thrombosis is one of the most severe complications of mechanical heart valve replacement ${ }^{[76-81]}$ although it may be observed less frequently in other types of valve substitutes. Both TTE and TEE must be performed in suspected prosthetic valve thrombosis. Two different clinical and echocardiographic presentations may occur.

In severely obstructive thrombosis, TTE is the first-line examination and may evidence an abnormal transprosthetic color flow jet, an elevated Doppler transprosthetic gradient, and a reduced effective orifice area. A high transvalvular gradient is of great value for the diagnosis of prosthetic thrombosis, especially when comparison with a reference value is available. Although direct evidence of valve
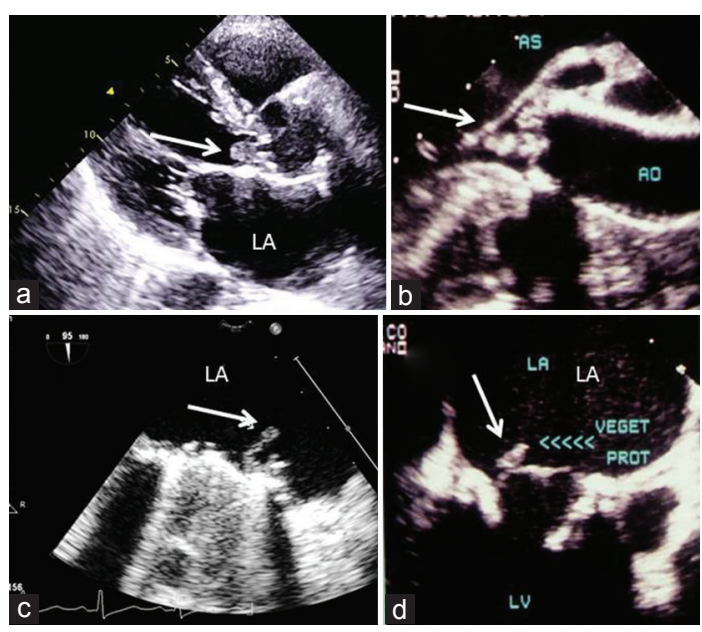

Figure 10: Vegetations in infective endocarditis (arrows). (a) Transthoracic echocardiogram parasternal long-axis view showing vegetation on native aortic valve; (b) transesophageal echocardiography long axis of endocarditis of native aortic valve; (c) transesophageal echocardiography visualization of vegetation on the atrial side of mechanical mitral valve; (d) transesophageal echocardiography showing endocarditis of bioprosthetic mitral valve. LA: Left atrium; LV: Left ventricle. thrombus may be obtained by TTE, TEE is the method of choice to diagnose the main signs of prosthetic thrombosis including restricted leaflet or disc motion, abnormal central regurgitation, loss of physiological regurgitant jets in mechanical valves, and direct visualization of thrombus or pannus formation. Cinefluoroscopy may also be useful in this setting. ${ }^{[82-84]}$ TEE is also very helpful for the assessment of the extent of thrombus formation. The risk of embolism and complications in prosthetic thrombosis have been related to the size of the thrombus, with a large thrombus $\left(>0.8 \mathrm{~cm}^{2}\right)$ being a major risk factor for complications of thrombolytic treatment and TEE may help in the choice between surgery and anticoagulant or thrombolytic therapy. ${ }^{[80]}$

Diagnosis of partial prosthetic thrombosis is more difficult, especially when obstruction is mild or absent. TTE is of limited value in this setting and TEE is the method of choice for the diagnosis of small prosthetic thrombosis.

\section{Intracardiac devices}

Both TTE and TEE are useful for the diagnosis of device thrombosis and/or IE.

A right-sided cardiac source of embolism must be suspected when an embolic event, particularly a pulmonary embolism occurs in a patient with an intracardiac device, including permanent pacemaker, implantable cardioverter defibrillators, or other intracardiac device, or when a paradoxical embolism is suspected.

\section{Minor Conditions}

\section{Mitral valve prolapse}

MVP is a very common cardiac condition estimated to occur (mainly in young women) in $2 \%$ of the general population. While in the past (also due to overestimation of the disease for echocardiographic technical reasons), several studies identified MVP in approximately one-third of patients under 45 years with cerebral ischemia, the most recent cohort and case-control studies have cast doubt on the role of uncomplicated MVP in stroke. Other studies identified the presence of mixomatous degeneration (with thickened or redundant leaflets) and supraventricular arrhythmias as risk factors for stroke. At present, the risk of thromboembolic complications in MVP is in general felt to be quite low (estimated at 1/6000 patient-years).

The mechanism of stroke in MVP is not clearly understood; one of the postulated etiological causes is that platelet-fibrin thrombi may form on the surface of the redundant leaflet tissue and embolize. More recently, an association between MVP and interatrial septal aneurysms has been clearly demonstrated and consequently, the potential of paradoxical emboli is present.

\section{Mitral annulus calcification}

Mitral annulus calcification (MAC) is a very common degenerative process. It refers to a chronic noninflammatory fibrous-calcification degeneration of the mitral annulus. 
Even though the Framingham heart study demonstrated a two-fold increase in the risk of stroke in these patients, no causal relationship between stroke and MAC has been established since MAC is a marker for generalized atherosclerosis. However, occasionally, mobile plaques may be clearly identified at the level of the calcified annulus by echocardiography (both TTE or TEE) and in those cases, the probability of an embolic source is much higher.

\section{Calcific aortic stenosis}

Calcific aortic stenosis is a very common disease including degenerative calcification, rheumatic, or congenital pathology. Embolic complications are very uncommon in these patients and the majority of cases of neurological events are occult or minor. Rarely, larger emboli have been associated with calcific aortic stenosis, mainly in procedural setting such as cardiac catheterization and percutaneous valvuloplasty or percutaneous valve implantation. TTE or TEE may rarely visualize small debris or mobile plaques at the level of the valve leaflets or annulus, further reinforcing the potential for an embolic event.

\section{Conclusions}

During the past two decades, enormous progress has been made in the noninvasive diagnosis of cardioembolic events. Transthoracic and TEE are the key diagnostic modalities for evaluation, diagnosis, and management of stroke, systemic and pulmonary embolism. In this regard, echocardiography is not only a powerful tool for the evaluation of cardioembolic sources of stroke but also to establish recommendations for the primary and secondary prevention of cardioembolic stroke.

\section{Financial support and sponsorship}

Nil.

\section{Conflicts of interest}

There are no conflicts of interest.

\section{ReFERENCES}

1. Pepi M, Evangelista A, Nihoyannopoulos P, Flachskampf FA, Athanassopoulos G, Colonna P, et al. Recommendations for echocardiography use in the diagnosis and management of cardiac sources of embolism: European Association of Echocardiography (EAE) (a registered branch of the ESC). Eur J Echocardiogr 2010;11:461-76.

2. Saric M, Armour AC, Arnaout MS, Chaudhry FA, Grimm RA, Kronzon I, et al. Guidelines for the use of echocardiography in the evaluation of a cardiac source of embolism. J Am Soc Echocardiogr 2016;29:1-42.

3. Ferro JM. Cardioembolic stroke: An update. Lancet Neurol 2003;2:177-88.

4. Brickner ME. Cardioembolic stroke. Am J Med 1996;100:465-74.

5. Goldstein LB, Adams R, Alberts MJ, Appel LJ, Brass LM, Bushnell CD, et al. Primary prevention of ischemic stroke: A guideline from the American Heart Association/American Stroke Association Stroke Council: Cosponsored by the Atherosclerotic Peripheral Vascular Disease Interdisciplinary Working Group; Cardiovascular Nursing Council; Clinical Cardiology Council; Nutrition, Physical Activity, and Metabolism Council; and the Quality of Care and Outcomes Research Interdisciplinary Working Group: The American Academy of Neurology affirms the value of this guideline. Stroke 2006;37:1583-633.

6. Sacco RL, Adams R, Albers G, Alberts MJ, Benavente O, Furie K, et al.
Guidelines for prevention of stroke in patients with ischemic stroke or transient ischemic attack: A statement for healthcare professionals from the American Heart Association/American Stroke Association Council on Stroke: Co-sponsored by the Council on Cardiovascular Radiology and Intervention: The American Academy of Neurology affirms the value of this guideline. Stroke 2006;37:577-617.

7. Adams HP Jr., del Zoppo G, Alberts MJ, Bhatt DL, Brass L, Furlan A, et al. Guidelines for the early management of adults with ischemic stroke: A guideline from the American Heart Association/American Stroke Association Stroke Council, Clinical Cardiology Council, Cardiovascular Radiology and Intervention Council, and the Atherosclerotic Peripheral Vascular Disease and Quality of Care Outcomes in Research Interdisciplinary Working Groups: The American Academy of Neurology affirms the value of this guideline as an educational tool for neurologists. Stroke 2007;38:1655-711.

8. Witt BJ, Brown RD Jr., Jacobsen SJ, Weston SA, Ballman KV, Meverden RA, et al. Ischemic stroke after heart failure: A community-based study. Am Heart J 2006;152:102-9.

9. Witt BJ, Gami AS, Ballman KV, Brown RD Jr., Meverden RA, Jacobsen SJ, et al. The incidence of ischemic stroke in chronic heart failure: A meta-analysis. J Card Fail 2007;13:489-96.

10. Nihoyannopoulos P, Smith GC, Maseri A, Foale RA. The natural history of left ventricular thrombus in myocardial infarction: A rationale in support of masterly inactivity. J Am Coll Cardiol 1989;14:903-11.

11. Weinsaft JW, Kim HW, Shah DJ, Klem I, Crowley AL, Brosnan R, et al. Detection of left ventricular thrombus by delayed-enhancement cardiovascular magnetic resonance prevalence and markers in patients with systolic dysfunction. J Am Coll Cardiol 2008;52:148-57.

12. Senior $\mathrm{R}$, Becher $\mathrm{H}$, Monaghan $\mathrm{M}$, Agati L, Zamorano J, Vanoverschelde JL, et al. Contrast echocardiography: Evidence-based recommendations by European Association of Echocardiography. Eur J Echocardiogr 2009; 10:194-212.

13. Kurt M, Shaikh KA, Peterson L, Kurrelmeyer KM, Shah G, Nagueh SF, et al. Impact of contrast echocardiography on evaluation of ventricular function and clinical management in a large prospective cohort. J Am Coll Cardiol 2009;53:802-10.

14. Fuster V, Rydén LE, Cannom DS, Crijns HJ, Curtis AB, Ellenbogen KA, et al. ACC/AHA/ESC 2006 guidelines for the management of patients with atrial fibrillation-executive summary: A report of the American College of Cardiology/American Heart Association Task Force on Practice Guidelines and the European Society of Cardiology Committee for Practice Guidelines (Writing Committee to Revise the 2001 Guidelines for the Management of Patients with Atrial Fibrillation). Eur Heart J 2006;27:1979-2030.

15. Agmon Y, Khandheria BK, Gentile F, Seward JB. Echocardiographic assessment of the left atrial appendage. J Am Coll Cardiol 1999;34:1867-77.

16. Zabalgoitia M, Halperin JL, Pearce LA, Blackshear JL, Asinger RW, Hart RG. Transesophageal echocardiographic correlates of clinical risk of thromboembolism in nonvalvular atrial fibrillation. Stroke Prevention in Atrial Fibrillation III Investigators. J Am Coll Cardiol 1998;31:1622-6.

17. Omran H, Jung W, Rabahieh R, Schimpf R, Wolpert C, Hagendorff A, et al. Left atrial chamber and appendage function after internal atrial defibrillation: A prospective and serial transesophageal echocardiographic study. J Am Coll Cardiol 1997;29:131-8.

18. Fatkin D, Kuchar DL, Thorburn CW, Feneley MP. Transesophageal echocardiography before and during direct current cardioversion of atrial fibrillation: Evidence for "atrial stunning" as a mechanism of thromboembolic complications. J Am Coll Cardiol 1994;23:307-16.

19. de Luca I, Colonna P, Sorino M, Del Salvatore B, De Luca L. New monodimensional transthoracic echocardiographic sign of left atrial appendage function. J Am Soc Echocardiogr 2007;20:324-32.

20. Moreira FC, Miglioransa MH, Hartmann IB, Rohde LE. Left atrial appendage assessment by second harmonic transthoracic echocardiography after an acute ischemic neurologic event. J Am Soc Echocardiogr 2005;18:206-12.

21. Gage BF, Waterman AD, Shannon W, Boechler M, Rich MW, Radford MJ. Validation of clinical classification schemes for predicting 
Celeste, et al.: Echocardiography and sources if embolism

stroke: Results from the National Registry of Atrial Fibrillation. JAMA 2001;285:2864-70.

22. Hylek EM, Evans-Molina C, Shea C, Henault LE, Regan S. Major hemorrhage and tolerability of warfarin in the first year of therapy among elderly patients with atrial fibrillation. Circulation 2007;115:2689-96.

23. Bernhardt P, Schmidt H, Hammerstingl C, Lüderitz B, Omran H. Patients with atrial fibrillation and dense spontaneous echo contrast at high risk a prospective and serial follow-up over 12 months with transesophageal echocardiography and cerebral magnetic resonance imaging. J Am Coll Cardiol 2005;45:1807-12.

24. Kamp O, Verhorst PM, Welling RC, Visser CA. Importance of left atrial appendage flow as a predictor of thromboembolic events in patients with atrial fibrillation. Eur Heart J 1999;20:979-85.

25. Klein AL, Grimm RA, Murray RD, Apperson-Hansen C, Asinger RW, Black IW, et al. Use of transesophageal echocardiography to guide cardioversion in patients with atrial fibrillation. $\mathrm{N}$ Engl $\mathrm{J}$ Med 2001;344:1411-20.

26. Sorino M, Colonna P, De Luca L, Carerj S, Oliva E, De Tommasi SM, et al. Post-cardioversion transesophageal echocardiography (POSTEC) strategy with the use of enoxaparin for brief anticoagulation in atrial fibrillation patients: The multicenter POSTEC trial (a pilot study). J Cardiovasc Med (Hagerstown) 2007;8:1034-42.

27. Lechat $\mathrm{P}$, Mas JL, Lascault G, Loron P, Theard M, Klimczac M, et al. Prevalence of patent foramen ovale in patients with stroke. N Engl J Med 1988;318:1148-52.

28. Webster MW, Smith HJ, Sharpe DN, Chancellor AM, Swift DL, Bass NM, et al. Patent foramen ovale in young stroke patients. Lancet 1988;2:11-2

29. Kerut EK, Norfleet WT, Plotnick GD, Giles TD. Patent foramen ovale: A review of associated conditions and the impact of physiological size. J Am Coll Cardiol 2001;38:613-23.

30. Konstantinides S, Geibel A, Kasper W, Olschewski M, Blümel L, Just H. Patent foramen ovale is an important predictor of adverse outcome in patients with major pulmonary embolism. Circulation 1998;97:1946-51.

31. Homma S, Sacco RL, Di Tullio MR, Sciacca RR, Mohr JP; PFO in Cryptogenic Stroke Study (PICSS) Investigators. Effect of medical treatment in stroke patients with patent foramen ovale: Patent foramen ovale in Cryptogenic Stroke Study. Circulation 2002;105:2625-31.

32. Flachskampf FA, Daniel WG. Closure of patent foramen ovale: Is the case really closed as well? Heart 2005;91:449-50.

33. Meier B. Closure of patent foramen ovale: Technique, pitfalls, complications, and follow up. Heart 2005;91:444-8.

34. Windecker S, Meier B. Is closure recommended for patent foramen ovale and cryptogenic stroke? Patent foramen ovale and cryptogenic stroke: To close or not to close? Closure: What else! Circulation 2008;118:1989-98.

35. Messé SR, Kasner SE. Is closure recommended for patent foramen ovale and cryptogenic stroke? Patent foramen ovale in cryptogenic stroke: Not to close. Circulation 2008;118:1999-2004.

36. Flachskampf FA. CON: The incidental finding of a patent foramen ovale during cardiac surgery: Should it always be repaired? Anesth Analg 2007;105:613-4.

37. Argenziano M. PRO: The incidental finding of a patent foramen ovale during cardiac surgery: Should it always be repaired? Anesth Analg 2007; 105:611-2.

38. Di Tullio MR, Sacco RL, Sciacca RR, Jin Z, Homma S. Patent foramen ovale and the risk of ischemic stroke in a multiethnic population. J Am Coll Cardiol 2007;49:797-802.

39. Meissner I, Khandheria BK, Heit JA, Petty GW, Sheps SG, Schwartz GL, et al. Patent foramen ovale: Innocent or guilty? Evidence from a prospective population-based study. J Am Coll Cardiol 2006;47:440-5.

40. Handke M, Harloff A, Olschewski M, Hetzel A, Geibel A. Patent foramen ovale and cryptogenic stroke in older patients. N Engl J Med 2007;357:2262-8.

41. Mas JL, Arquizan C, Lamy C, Zuber M, Cabanes L, Derumeaux G, et al. Recurrent cerebrovascular events associated with patent foramen ovale, atrial septal aneurysm, or both. N Engl J Med 2001;345:1740-6.

42. Stone DA, Godard J, Corretti MC, Kittner SJ, Sample C, Price TR, et al. Patent foramen ovale: Association between the degree of shunt by contrast transesophageal echocardiography and the risk of future ischemic neurologic events. Am Heart J 1996;131:158-61.

43. Fox ER, Picard MH, Chow CM, Levine RA, Schwamm L, Kerr AJ. Interatrial septal mobility predicts larger shunts across patent foramen ovales: An analysis with transmitral Doppler scanning. Am Heart J 2003;145:730-6.

44. Pinto FJ. When and how to diagnose patent foramen ovale. Heart 2005;91:438-40

45. Kühl HP, Hoffmann R, Merx MW, Franke A, Klötzsch C, Lepper W, et al. Transthoracic echocardiography using second harmonic imaging: Diagnostic alternative to transesophageal echocardiography for the detection of atrial right to left shunt in patients with cerebral embolic events. J Am Coll Cardiol 1999;34:1823-30.

46. Clarke NR, Timperley J, Kelion AD, Banning AP. Transthoracic echocardiography using second harmonic imaging with Valsalva manoeuvre for the detection of right to left shunts. Eur J Echocardiogr 2004;5:176-81.

47. Agmon Y, Khandheria BK, Meissner I, Schwartz GL, Petterson TM, O'Fallon WM, et al. Relation of coronary artery disease and cerebrovascular disease with atherosclerosis of the thoracic aorta in the general population. Am J Cardiol 2002;89:262-7.

48. Demopoulos LA, Tunick PA, Bernstein NE, Perez JL, Kronzon I. Protruding atheromas of the aortic arch in symptomatic patients with carotid artery disease. Am Heart J 1995;129:40-4.

49. Tunick PA, Kronzon I. Atheromas of the thoracic aorta: Clinical and therapeutic update. J Am Coll Cardiol 2000;35:545-54.

50. Nishino M, Masugata H, Yamada Y, Abe H, Hori M, Kamada T. Evaluation of thoracic aortic atherosclerosis by transesophageal echocardiography. Am Heart J 1994;127:336-44.

51. Vaduganathan P, Ewton A, Nagueh SF, Weilbaecher DG, Safi HJ, Zoghbi WA. Pathologic correlates of aortic plaques, thrombi and mobile "aortic debris" imaged in vivo with transesophageal echocardiography. J Am Coll Cardiol 1997;30:357-63.

52. Laperche T, Laurian C, Roudaut R, Steg PG. Mobile thromboses of the aortic arch without aortic debris. A transesophageal echocardiographic finding associated with unexplained arterial embolism. The Filiale Echocardiographie de la Société Française de Cardiologie. Circulation 1997;96:288-94.

53. Dressler FA, Craig WR, Castello R, Labovitz AJ. Mobile aortic atheroma and systemic emboli: Efficacy of anticoagulation and influence of plaque morphology on recurrent stroke. J Am Coll Cardiol 1998;31:134-8.

54. Amarenco P, Cohen A, Tzourio C, Bertrand B, Hommel M, Besson G, et al. Atherosclerotic disease of the aortic arch and the risk of ischemic stroke. N Engl J Med 1994;331:1474-9.

55. Transesophageal echocardiographic correlates of thromboembolism in high-risk patients with nonvalvular atrial fibrillation. The Stroke Prevention in Atrial Fibrillation Investigators Committee on Echocardiography. Ann Intern Med 1998;128:639-47.

56. Dávila-Román VG, Murphy SF, Nickerson NJ, Kouchoukos NT, Schechtman KB, Barzilai B. Atherosclerosis of the ascending aorta is an independent predictor of long-term neurologic events and mortality. J Am Coll Cardiol 1999;33:1308-16.

57. Meissner I, Khandheria BK, Sheps SG, Schwartz GL, Wiebers DO, Whisnant JP, et al. Atherosclerosis of the aorta: Risk factor, risk marker, or innocent bystander? A prospective population-based transesophageal echocardiography study. J Am Coll Cardiol 2004;44:1018-24.

58. Montgomery DH, Ververis JJ, McGorisk G, Frohwein S, Martin RP, Taylor WR. Natural history of severe atheromatous disease of the thoracic aorta: A transesophageal echocardiographic study. J Am Coll Cardiol 1996;27:95-101.

59. Burke A, Jeudy J Jr., Virmani R. Cardiac tumours: An update: Cardiac tumours. Heart 2008;94:117-23.

60. Aggarwal SK, Barik R, Sarma TC, Iyer VR, Sai V, Mishra J, et al. Clinical presentation and investigation findings in cardiac myxomas: New insights from the developing world. Am Heart J 2007;154:1102-7.

61. Neragi-Miandoab S, Kim J, Vlahakes GJ. Malignant tumours of the heart: A review of tumour type, diagnosis and therapy. Clin Oncol (R Coll Radiol) 2007;19:748-56.

62. Tornos P, Iung B, Permanyer-Miralda G, Baron G, Delahaye F, Gohlke-Bärwolf $\mathrm{CH}$, et al. Infective endocarditis in Europe: Lessons from the Euro heart survey. Heart 2005;91:571-5. 
Celeste, et al.: Echocardiography and sources if embolism

63. Moreillon P, Que YA. Infective endocarditis. Lancet 2004;363:139-49.

64. Thuny F, Avierinos JF, Tribouilloy C, Giorgi R, Casalta JP, Milandre L, et al. Impact of cerebrovascular complications on mortality and neurologic outcome during infective endocarditis: A prospective multicentre study. Eur Heart J 2007;28:1155-61.

65. Mügge A, Daniel WG. Echocardiographic assessment of vegetations in patients with infective endocarditis: Prognostic implications. Echocardiography 1995;12:651-61.

66. Habib G. Embolic risk in subacute bacterial endocarditis: Determinants and role of transesophageal echocardiography. Curr Cardiol Rep 2003;5:129-36.

67. Di Salvo G, Habib G, Pergola V, Avierinos JF, Philip E, Casalta JP, et al. Echocardiography predicts embolic events in infective endocarditis. J Am Coll Cardiol 2001;37:1069-76.

68. Thuny F, Di Salvo G, Belliard O, Avierinos JF, Pergola V, Rosenberg V, et al. Risk of embolism and death in infective endocarditis: Prognostic value of echocardiography: A prospective multicenter study. Circulation $2005 ; 112: 69-75$.

69. Durack DT, Lukes AS, Bright DK. New criteria for diagnosis of infective endocarditis: Utilization of specific echocardiographic findings. Duke Endocarditis Service. Am J Med 1994;96:200-9.

70. Habib G, Hoen B, Tornos P, Thuny F, Prendergast B, Vilacosta I, et al. Guidelines on the prevention, diagnosis, and treatment of infective endocarditis (new version 2009): The Task Force on the Prevention, Diagnosis, and Treatment of Infective Endocarditis of the European Society of Cardiology (ESC). Endorsed by the European Society of Clinical Microbiology and Infectious Diseases (ESCMID) and the International Society of Chemotherapy (ISC) for Infection and Cancer. Eur Heart J 2009;30:2369-413.

71. Habib G. Management of infective endocarditis. Heart 2006;92:124-30.

72. Rohmann S, Erbel R, Görge G, Makowski T, Mohr-Kahaly S, Nixdorff $\mathrm{U}$, et al. Clinical relevance of vegetation localization by transoesophageal echocardiography in infective endocarditis. Eur Heart J 1992;13:446-52.

73. Vilacosta I, Graupner C, San Román JA, Sarriá C, Ronderos R, Fernández $\mathrm{C}$, et al. Risk of embolization after institution of antibiotic therapy for infective endocarditis. J Am Coll Cardiol 2002;39:1489-95.

74. Sanfilippo AJ, Picard MH, Newell JB, Rosas E, Davidoff R, Thomas JD, et al. Echocardiographic assessment of patients with infectious endocarditis: Prediction of risk for complications. J Am Coll Cardiol 1991;18:1191-9.

75. Mügge A, Daniel WG, Frank G, Lichtlen PR. Echocardiography in infective endocarditis: Reassessment of prognostic implications of vegetation size determined by the transthoracic and the transesophageal approach. J Am Coll Cardiol 1989;14:631-8.

76. Horstkotte D, Burckhardt D. Prosthetic valve thrombosis. J Heart Valve Dis 1995;4:141-53.

77. Roudaut R, Serri K, Lafitte S. Thrombosis of prosthetic heart valves: Diagnosis and therapeutic considerations. Heart 2007;93:137-42.

78. Habib G, Cornen A, Mesana T, Monties JR, Djiane P, Luccioni R. Diagnosis of prosthetic heart valve thrombosis. The respective values of transthoracic and transoesophageal Doppler echocardiography. Eur Heart J 1993;14:447-55.

79. Gueret P, Vignon P, Fournier P, Chabernaud JM, Gomez M, LaCroix P, et al. Transesophageal echocardiography for the diagnosis and management of non obstructive thrombosis of mechanical mitral valve prosthesis. Circulation 1995;91:103-10.

80. Tong AT, Roudaut R, Ozkan M, Sagie A, Shahid MS, Pontes Júnior SC, et al. Transesophageal echocardiography improves risk assessment of thrombolysis of prosthetic valve thrombosis: Results of the international PRO-TEE registry. J Am Coll Cardiol 2004;43:77-84.

81. Alpert JS. The thrombosed prosthetic valve: Current recommendations based on evidence from the literature. J Am Coll Cardiol 2003;41:659-60.

82. Lancellotti P, Pibarot P, Chambers J, Edvardsen T, Delgado V, Dulgheru $\mathrm{R}$, et al. Recommendations for the imaging assessment of prosthetic heart valves: A report from the European Association of Cardiovascular Imaging endorsed by the Chinese Society of Echocardiography, the Inter-American Society of Echocardiography, and the Brazilian Department of Cardiovascular Imaging. Eur Heart J Cardiovasc Imaging 2016;17:589-90.

83. Muratori M, Montorsi P, Maffessanti F, Teruzzi G, Zoghbi WA, Gripari P, et al. Dysfunction of bileaflet aortic prosthesis: Accuracy of echocardiography versus fluoroscopy. JACC Cardiovasc Imaging 2013;6:196-205.

84. Pepi M, Muratori M, Maffessanti F, Mirea O, Montorsi P. High trans-prosthetic gradients and prosthetic aortic valve dysfunction: The need for an accurate multimodality imaging approach. J Cardiovasc Echography 2012;22:159-65. 